\title{
Viscous Three-Dimensional Simulation of Flow in an Axial Low Pressure Compressor at Engine Icing Operating Points
}

\author{
David L. Rigby ${ }^{1}$ \\ Vantage Partners Limited, Cleveland, OH, 44135 \\ Ali A. Ameri ${ }^{2}$ \\ The Ohio State University, Columbus, $\mathrm{OH}$ \\ and \\ Joe Veres $^{3}$ and Philip C.E. Jorgenson ${ }^{4}$ \\ NASA Glenn Research Center, Cleveland, OH, 44135
}

\begin{abstract}
Viscous three-dimensional simulations of the Honeywell ALF502R-5 low pressure compressor (sometimes called a booster) using the NASA Glenn code GlennHT have been carried out. A total of ten simulations were produced. Five operating points are investigated, with each point run with two different wall thermal conditions. These operating points are at, or near, points where engine icing has been determined to be likely. In the future, the results of this study will be used for further analysis such as predicting collection efficiency of ice particles and ice growth rates at various locations in the compressor. A mixing plane boundary condition is used between each blade row, resulting in convergence to steady state within each blade row. The k-omega turbulence model of Wilcox, combined with viscous grid spacing near the wall on the order of one, is used to resolve the turbulent boundary layers. For each of the operating points, heat transfer coefficients are generated on the blades and walls. The heat transfer coefficients are produced by running the operating point with two different wall thermal conditions and then solving simultaneously for the heat transfer coefficient and adiabatic wall temperature at each point. Average Nusselt numbers are calculated for the most relevant surfaces. The values are seen to scale with Reynolds number to approximately a power of 0.7. Additionally, images of surface distribution of Nusselt number are presented. Qualitative comparison between the five operating points show that there is relatively little change in the character of the distribution. The dominant observed effect is that of an overall scaling, which is expected due to Reynolds number differences. One interesting aspect about the Nusselt number distribution is observed on the casing (outer diameter) downstream of the exit guide vanes (EGVs). The Nusselt number is relatively high between the pairs of EGVs, with two lower troughs downstream of each EGV trailing edge. This is of particular interest since rather complex ice shapes have been observed in that region.
\end{abstract}

\footnotetext{
${ }^{1}$ Senior Research Engineer, Vantage Partners, LLC.

${ }^{2}$ Research Scientist, Department of Mechanical and Aerospace Engineering, The Ohio State University.

${ }^{3}$ Aerospace Engineer, Turbomachinery and Heat Transfer Branch, NASA Glenn Research Center.

${ }^{4}$ Aerospace Engineer, Turbomachinery and Heat Transfer Branch, NASA Glenn Research Center.
} 


\section{Introduction}

Engine icing has been identified as an important safety issue [1,2]. Many engine icing events have been documented which result in loss of thrust. These events occur at high altitude $(\sim 40,000 \mathrm{ft})$ when flying through high ice water content $(\mathrm{HIWC})$ regions $\left(>2 \mathrm{~g} / \mathrm{m}^{3}\right)$. Recently a number of known engine ice crystal icing power-loss event simulations were performed in the NASA PSL engine icing test cell [3]. The engine studied was the Honeywell ALF502R-5, which in the past had experienced rollback [4]. Honeywell has since produced modified versions of this engine which no longer exhibit susceptibility to engine icing. In the NASA experiment they were able to test many operating points, at various simulated altitudes, and with varying amounts of ice water content. The experiment was able to produce many rollback events.

A one dimensional analysis code, COMDES, has been used to simulate the ALF502R-5 engine at many operating points [5-7]. Based on experimental observations and analysis results provided by Honeywell, the COMDES results are considered to be quite good for determining average aero-thermodynamic quantities throughout the fan and low pressure compressor.

The present work is an effort to produce higher fidelity results to better understand the flow within the engine. In addition, the flow field results will be passed on to the LEWICE3D software [9] to investigate what happens to the ice particles as they travel through the engine. Three dimensional viscous simulations using the NASA GlennHT code $[8,15]$ are produced for five operating points. A mixing plane approach is adopted at planes between stationary and rotating blade rows. The GlennHT code can do time accurate viscous simulations, but in the interest of using minimum computational resources the analysis is simplified. In a previous paper [10] inviscid simulations were carried out on eight operating points.

For each of the operating points two simulations are performed. The first simulation imposed adiabatic conditions at all of the no-slip walls. The second simulation holds the no-slip walls at the inlet total temperature. The fixed wall temperature is chosen somewhat arbitrarily, owing to the assumption that the resulting heat transfer coefficient will be independent of the wall temperature choice. A summary of the wall heat transfer coefficients and adiabatic wall temperature are presented.

\section{Description of the geometry}

The numerical simulation produced for the present study corresponds to a set of experiments carried out in the NASA Propulsion Systems Lab (PSL) test cell three. Figure 1 shows a schematic of the PSL-3 setup. Flow is from left to right. Spray bars are located upstream to introduce ice or water droplets. Downstream of the spray bars is a large contraction where the entire flow of the tunnel is directed into the engine. Results in the present work incorporate a numerical inlet placed at the constant area cross section between the contraction and the engine. Figure 2 shows a schematic of the fan and low pressure compressor of the engine. A total of five blade rows are modeled. From inlet to exit the blade rows are fan, Inlet Guide Vane (IGV), Rotor, Exit Guide Vane 1 (EGV1) and EGV2. Neither the struts in the core flow nor the struts in the bypass flow were simulated.

Figure 3 shows an outline of the numerical blocks. Flow is from left to right. A constant radius surface is shown colored by stagnation pressure to assist in visualizing the blades. In Figure 3 the fan is easily visible near the center with the remaining blades appearing smaller and to the right. Figure 4 is similar to Figure 3, but is zoomed in more to show more detail in the core. In this figure the trailing edge of the fan is visible to the left, followed by the IGV, Rotor, EGV1, and EGV2, from left to right.

A single blade in each blade row is all that is gridded because a mixing plane approximation is used between stationary and rotating blade rows. Figure 5 shows the different parts of the grid with labels for the zones and interfaces between each region. The boundary between zones is referred to as a General Interface (GIF). The total number of grid cells in the viscous grid is approximately 1 million, contained in 375 blocks. A large number of blocks are used to enable parallel processing using many CPUs.

Figure 6 shows a comparison of the viscous and inviscid grids, with every other grid point removed for clarity. The starting point of the viscous grid was the inviscid grid from previous work. Viscous clustering was then applied to each of the solid walls. Grid spacing near the wall is set to produce y-plus values on the order of unity.

\section{Description of the flow analysis code}

\section{Overview of GlennHT}

GlennHT is a NASA in-house code which has been used and developed over the course of many years [8,15]. It uses multi-block structured grids to solve the three-dimensional Navier-Stokes equations. For the present analysis, the GlennHT code is used to solve the steady Reynolds Averaged Navier-Stokes equations for turbulent viscous flow using the Wilcox K-omega turbulence model [13].

\section{Boundary Conditions}

For each simulation, boundary conditions are set to produce the same inlet total conditions and mass flow as the respective case using the COMDES software [7,12]. The COMDES simulation does not include the bypass flow, so the bypass mass flow was set to match the result from the engine company customer deck. For each case, the core flow represented approximately $13 \%$ of the overall flow. The desired mass flow in each region (core and bypass) was produced by adjusting the exit static pressure.

Page 2 of 17 
At each interface between stationary and rotating blade rows a mixing plane approximation is used. At these locations, the results from the flow domain are averaged in the circumferential direction, producing a radial distribution of relevant quantities. Global adjustments are made to the upstream static pressure to ensure that the mass balance across each mixing plane is within $0.1 \%$.

During the process of running the present cases it was observed that the fan was very likely to have separated flow present when the mass flow was driven to the desired operating point. Based on experimental observations and engine company prediction, the separation was believed to be incorrect. In addition, the hub region (inner radius) near the EGVs also often contained separated regions. In an effort to achieve a physically correct solution several modifications to the simulation boundary conditions were attempted. Since the main interest of the present work is to investigate the heat transfer on the core blades and the outer casing of the core, it was decided to let the core hub wall and the fan have a slip boundary condition. This helped alleviate the separation near the EGVs, but the fan was still problematic. At that point it was surmised that the mixing plane boundary condition may be an issue. In hindsight, it may have been better to locate the mixing plane farther upstream of the fan face. For future simulations, the mixing plane will be placed farther upstream. In its present implementation, the mixing plane imposes radial distributions of total pressure, total temperature, and angle on the downstream blade row. A radial distribution of static pressure is imposed on the upstream blade row. One shortcoming of this simplified approach is that, at each radial location, a single angle is imposed across the entire pitch. In addition, the flow in the downstream blade has no effect on the flow angle other than its own static pressure controlling the mass flow rate. In the future, a more advanced mixing plane approximation will be implemented. However, for the present task at hand it was determined that it was prudent to impose a small amount of upstream swirl to keep the fan from separating. While this is not a very satisfying solution, it was observed that when the fan is running attached the performance was much closer to the expected behavior than if it was allowed to separate.

\section{Description of Operating Points}

Five operating points were simulated using the GlennHT code. The five points are summarized in Table 1 . Note that the inlet total temperature was raised by a small amount, relative to the experimental value, in the COMDES simulations to account for the heat introduced by the anti-icing air flow in the IGV. The present simulations use inlet conditions consistent with those used in the COMDES analysis [12]. The GlennHT simulation does not take into account any effect from the ice particles in the present work.

The case labeled LF01_433 (also referred to as PSL_DP0443) will be used as the normalizing case. It corresponds to a flight called FLT_850 when a rollback event occurred with the same engine tested when it was on the wing. The other four operating points are taken from the second ice crystal engine test at the NASA Glenn Propulsion System Laboratory (PSL) and have been discussed in Veres et. al. [12]. The point LF11_093 is very similar to the point from the first engine test referred to as LF01_443 in the past. The point LF11_344 is at slightly higher altitude condition of $31 \mathrm{k}$ feet, as compared to $29 \mathrm{k}$ feet for point LF01_433. The points LF11_416 and LF11_424 are a condition corresponding to 5k feet. The point LF11_416 is running at similar corrected conditions to LF01_433, while LF11_424 is running at lower mass flow and corresponding lower RPM. It is of interest to note that the $5 \mathrm{k}$ feet data points are running at much higher Reynolds numbers owing to the increased density and pressure. Reynolds number is calculated based on core mass flow and inlet viscosity. The length scaled used is not relevant since we are only presenting ratios of Reynolds numbers.

\section{Results}

\section{Brief explanation of results presentation}

Results discussing the performance of the engine have been previously presented [10]. The results presented in this paper focus on the heat transfer coefficient distribution. The heat transfer coefficient is presented in dimensionless form as Nusselt number. First a discussion of averages over various regions is presented, followed by a more detail look at the local variations in regions of icing interest.

\section{Discussion of average heat transfer coefficient results}

Figure 7 shows the average Nusselt number over each of the core blades (IGV, Rotor, EGV1, EGV2), and also on the outer casing of the core above each blade (IGVcase, RotorCase, and EGVcase). Note that the area for the EGVcase includes the casing above both EGVs, as well as all the way to the numerical exit. It also includes the BypassHub, although that is not of particular interest in the present work. For each region, the different color bars represent the five different cases. These averages were generated using the Fieldview software from Intelligent Light. General trends that can be observed are the following:

- Average Nusselt numbers on the blades increase as one progresses through the machine.

- While the RotorCase produces a higher average than the IGVcase, the average Nusselt number on the EGVcase is consistently lower than any other surface considered.

- $\quad$ For each surface, variations between operating points is consistent with what would be expected owing to changes in Reynolds number. Over all of the surfaces, the variation with respect to Reynolds number occurred at an average power of about 0.7 . This means that if you know the Reynolds number and Nusselt number at one condition and the Reynolds number at a second condition, then you could approximate the Nusselt number at the second condition by taking the ratio of Reynold numbers raised to the 0.7 power and multiplying by the first Nusselt number. 
Figure 8 is similar to figure 7 except that it show average adiabatic wall temperature instead of Nusselt number. General trends that can be observed are the following:

- For each operating point, the adiabatic wall temperature increases as one progresses through the machine (on both blades and casing). This is to be expected because of the work done by the rotating blades.

- Four of the cases produce similar results owing to the fact that they are running at similar corrected conditions. The case, LF11 424 produces a smaller temperature rise because it is running slower.

\section{Discussion of local heat transfer coefficient results}

Figure 9 shows the core casing region downstream of the EGVs colored by Nusselt number. This view is similar to a camera angle used in the LF11 test. Note that flow is from right to left and the pressure side of the EGV2 is visible on the right side of each figure. Only four cases are included because the result for LF01_433 is essentially indistinguishable from the LF11_093 result. Each part of the figure a-d is drawn with same scale. An overall view confirms what was seen in the average result; that is, that the level of Nusselt number scales with Reynolds number. The variation of the Nusselt number distribution is very similar between all four runs. A low region is observed downstream of the EGVs (not referring to the small region just downstream of the trailing edge, but rather the larger region farther downstream). Further, it can be seen that there are actually two streaks of low Nusselt number, one emanating from each EGV trailing edge. This is a region where highly complex ice growth was observed experimentally. It would seem likely that the distribution of Nusselt number shown here would be conducive to the ice shapes observed [11,12,14]. Obviously, the supply of ice and water particles to the region would also be strong contributing factors.

Figure 10-14 show the blades and casing colored by Nusselt number. The "a" and "b" parts of each figure are positioned so one could imagine the center of the machine between the two. In these figures flow is from left to right. Generally, each blade surface follows a similar trend. The trend on each blade surface is to have a very high Nusselt number at the leading edge which reduces and becomes quite uniform over the remainder of the surface. There is very little spanwise variation, with the exception of the rotor blade. The suction surface of the rotor blade (as can be seen in the "b" portion of figures 10-14) has little spanwise variation except for a small region near the trailing edge tip where a low region occurs. On the rotor pressure side (as can be seen in the "a" portion of figures 10-14) a significant region of reduced values of Nusselt are observed extending as a wedge from leading edge and widening toward the trailing edge. This wedge of reduced Nusselt number is likely due to the scraping of the rotor blade past the stationary casing. It should be noted that this simulation still assumes a zero tip clearance, so no flow escapes through the tip region. By comparing figures 10-14 to each other, it is apparent that the main differences are that the overall levels scale up as Reynolds increases. Beyond that, the general shape of the distribution changes little. The observation that the distributions look similar holds true even for the case LF11_424 which was running at lower corrected conditions. If this trend holds true in reality (after all this is a numerical result looking at a region where Nusselt number data is not available) it could bode well for attempts to scale icing conditions to lower altitudes to simplify testing. As a further demonstration of the similar distributions; figure 15 shows the result for LF11_416 with the scale modified to double the range. Referring to figure 7, one will recall that the averages for case LF11_416 are roughly twice those of LF11_093. Comparing figure 15 to figure 10 demonstrates the very similar distributions.

\section{Summary}

Three-dimensional numerical simulations were performed on the fan and low pressure compressor of the Honeywell ALF502R-5 engine as tested in the NASA PSL wind tunnel. Previous work had focused on the aerodynamic performance of the machine, while this work presents results of heat transfer coefficients in the region of suspected engine icing. It was determined that, prior to attempting a more comprehensive list of operating points on a fine mesh, some improvements to the numerical implementation should be investigated. The main factor that will be investigated will be to consider a higher fidelity implementation of the mixing plane approximation. Having said that, the present results do offer insight into the level and distribution of heat transfer coefficients. For each of the five operating points, two cases were converged. One case imposed an adiabatic wall condition on no-slip walls, while the second case held the no-slip walls at a fixed temperature. Then, using the result from the two cases, the Nusselt number and adiabatic wall temperature were solved for simultaneously at each wall node. Averages were generated on each blade, as well as on the casing (outer wall) around each blade. It was observed that the average Nusselt number on the blades increases in the flow direction (i.e.

IGV $<$ Rotor $<$ EGV1 $<$ EGV2). The average Nusselt number on the case above the IGV is less than above the Rotor, but the case above the EGVs has the lowest values for each operating point. In addition to the average Nusselt number on the case above the EGVs being relatively low, streaks of low values are observed downstream of each EGV trailing edge. These streaks, it is surmised, could contribute to the complexity of ice shapes seen in the experimental results.

\section{References}

1. Mason, J; Strapp, W and Chow, P; “The Ice Particle Threat to Engines in Flight”, 44th AIAA Aerospace Sciences Meeting, v4, 2006, pp24452465 .

2. Mazzawy R.S., Strapp J.W.; “Appendix D - An Interim Icing Envelope; SAE 2007-01-3311; SAE 2007 Aircraft and Engine Icing International Conference; Seville, Spain, November 2007.

3. Oliver, M., "Validation Ice Crystal Icing Engine Test in the Propulsion Systems Laboratory at NASA Glenn Research Center," AIAA 20142898, 2014.

4. Goodwin, R.V. and Dischinger, D.G.; "Turbofan Ice Crystal Rollback Investigation and Preparations Leading to Inaugural Ice Crystal Engine Test at NASA PSL-3 test Facility,” AIAA 2014-2895, 2014.

Page 4 of 17 
5. Veres, J. P., Jorgenson, P. C. E., "Modeling Commercial Turbofan Engine Icing Risk with Ice Crystal Ingestion”, AIAA $2013-2679$.

6. Veres, J. P., Jorgenson, P. C. E., Wright, W. B., Struk, P., "A Model to Assess the Risk of Ice Accretion due to Ice Crystal Ingestion in a Turbofan Engine and its Effects on Performance", AIAA 2012-3038.

7. Veres, J. P., Jorgenson, P. C. E., Coennen, R., “Modeling of Commercial Turbofan Engine with Ice Crystal Ingestion; Follow-On,” AIAA 20142899.

8. Steinthorsson, E., Liou, M., and Povinelli, L.,'Development of an Explicit Multiblock/Multigrid Flow Solver for Viscous Flows in Complex Geometries," AIAA-93-2380 (NASA TM-106356), 1993.

9. Bidwell, C., Potapczuk, M., "User's Manual for the NASA Lewis Three-Dimensional Ice Accretion Code (LEWICE3D),” NASA TM-105974, December 1993.

10. Rigby, D. L., Veres, J., Bidwell, C.; "Three Dimensional Simulation of Flow in an Axial Pressure Compressor at Engine Icing Operating Points", SAE 2015 International Conference on Icing of Aircraft, Engines, and Structures, Prague, Czech Republic, June 2015 , 15 ICE-0139.

11. Goodwin, R.V. and Fuleki D.; "Engine Preparation and Instrumentation for the Second Ice Crystal Engine Test at NASA PSL-3 test Facility," AIAA 2016-3892, 2016.

12. Veres, J. P., Jorgenson, P. C. E., Jones, S.M., "Modeling of Highly Instrumented Honeywell Turbofan Engine with Ice Crystal Ingestion in the NASA Propulsion System Laboratory," AIAA 2016-3895.

13. Wilcox, D.C., 1994, Turbulence Modeling for CFD, Third Edition, DCW Industries, Inc., La Canada, CA., 2004.

14. Flegel, A. B., and Oliver, M. J. "Preliminary Results from a Heavily Instrumented Engine Ice Crystal Icing Test in a Ground Based Altitude Test Facility," 8th AIAA Atmospheric and Space Environments Conference, AIAA-2016-3894, 2016.

15. Ameri AA, Rigby DL, Steinthorsson E, Heidmann J, Fabian JC. Unsteady Analysis of Blade and Tip Heat Transfer as Influenced by the Upstream Momentum and Thermal Wakes. ASME. J. Turbomach. 2010;132(4):041007-041007-7. doi:10.1115/1.3213549.

\section{Acknowledgments}

This work is supported by the Advanced Aircraft Icing (AAI) Subproject of the NASA Advanced Air Transport Technology Project (AATT) under NASA's Advanced Air Vehicle Program (AAVP), and is in response to the Engine Icing Technical Challenge. The authors would also like to thank Anthony Nerone, manager of the NASA Advanced Aircraft Icing subproject for supporting this work.

\section{Nomenclature}

$\begin{array}{ll}\text { EGV } & \text { Exit Guide Vane } \\ \text { IGV } & \text { Inlet Guide Vane } \\ \text { M_inf } & \text { Mach number at inlet } \\ \text { N1 } & \text { Physical rotation rate as percentage of design point } \\ \text { PSL DP } & \text { Propulsion Systems Lab Data Point } \\ \text { Pt_inf } & \text { Total pressure at inlet } \\ \text { Tt_inf } & \text { Total temperature at inlet }\end{array}$




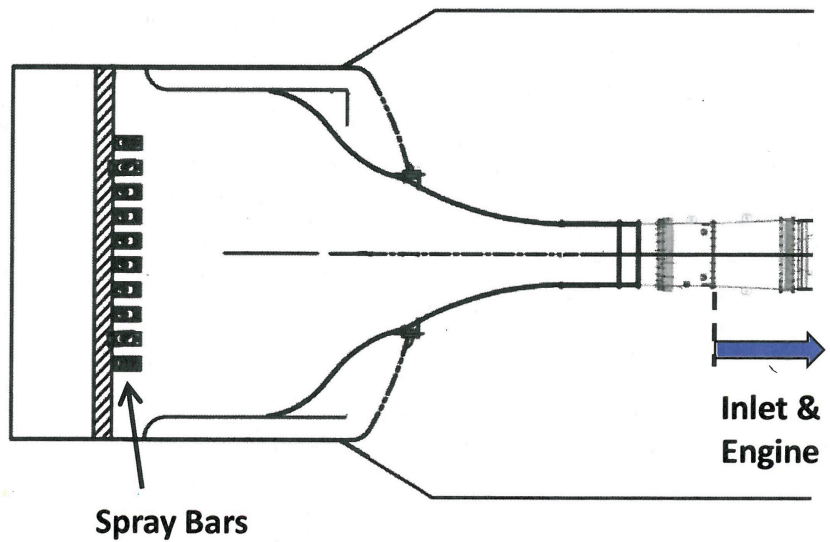

Figure 1 Inlet duct in the PSL facility connects directly to the engine flange.

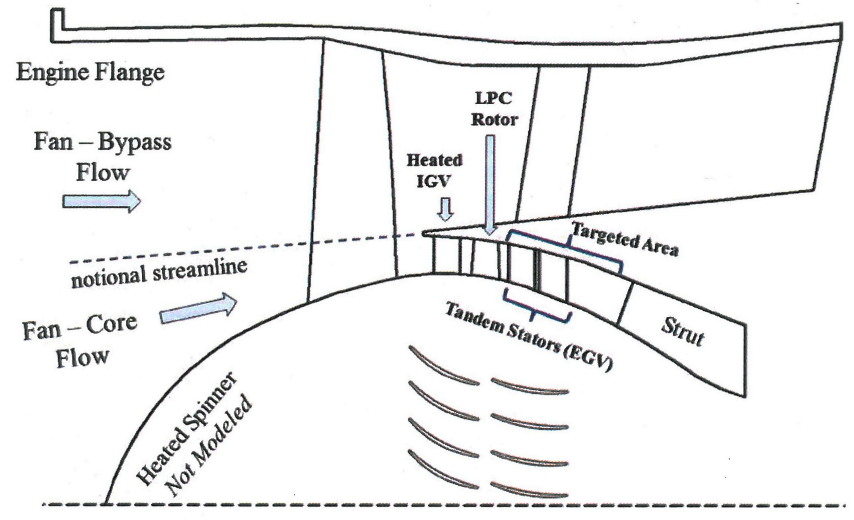

Figure 2 Schematic of the fan and low pressure compressor portion of the engine in the PSL with ice crystal ingestion 


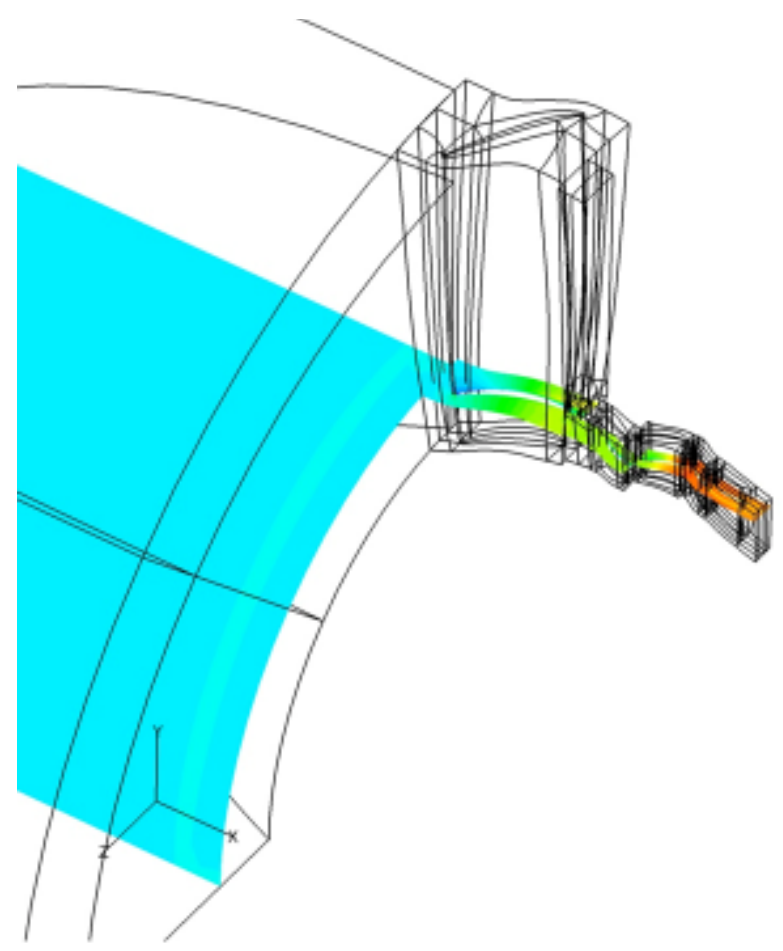

Figure 3 View showing Fan and LPC.

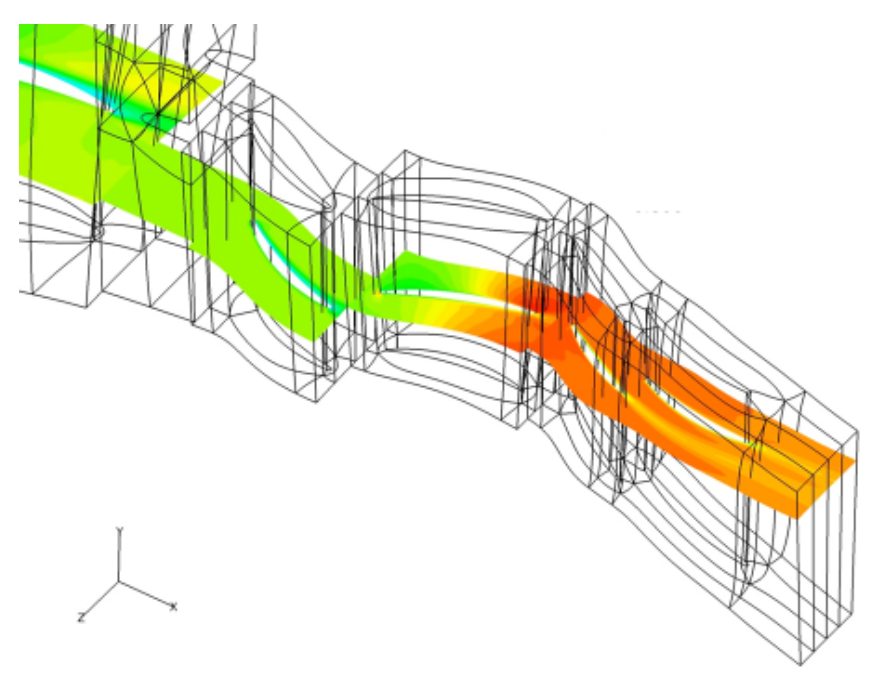

Figure 4 View showing only LPC. 


\section{Schematic of ALF502 Grid}

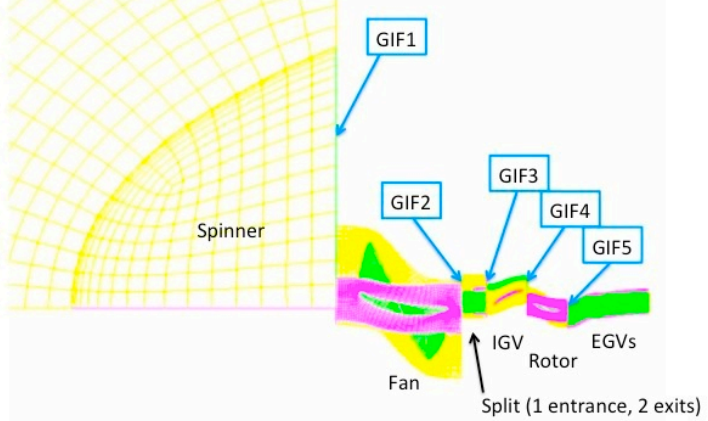

GIF = General Interface (i.e. Mixing Plane)

Figure 5 Schematic of ALF502R-5 grid

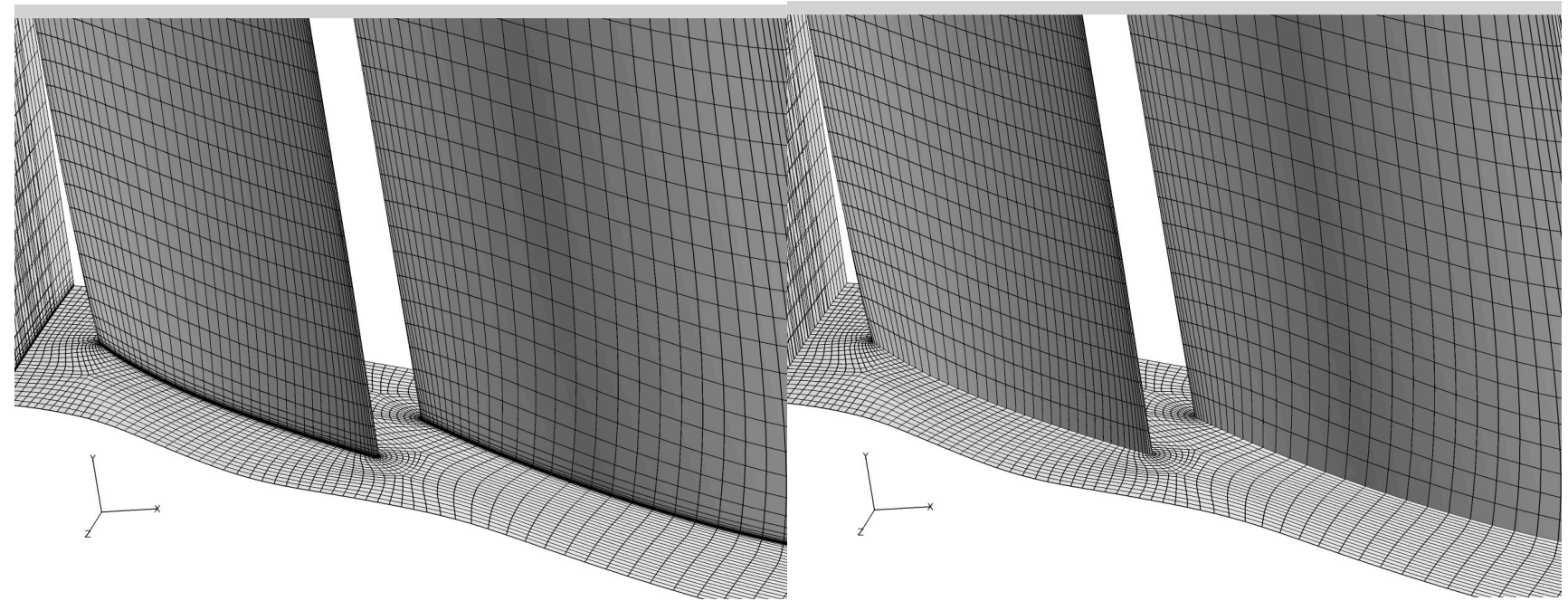

Figure 6 Comparison of Viscous (left) and Inviscid (right) grid, with every other grid point removed for clarity. 
Table 1. Summary of test conditions analyzed. Dimensional quantities normalized by FLT_850 (i.e. LF01_443) conditions.

\begin{tabular}{|l|l|l|l|l|l|l|}
\hline Event & PSL DP & Pt_inf & M_inf & Tt_inf & N1 $(\%)$ & Re/Re_443 \\
\hline FLT_850 & LF01_443 & 1.000 & 0.56 & 1.000 & 80 & 1.00 \\
\hline & LF11_093 & 0.983 & 0.52 & 0.967 & 80 & 0.963 \\
\hline Cold E+6F & LF11_344 & 0.92 & 0.56 & 0.959 & 80 & 0.893 \\
\hline 5k anchor & LF11_416 & 2.25 & 0.19 & 0.945 & 76 & 2.346 \\
\hline 5k, 55\% N1 & LF11_424 & 2.26 & 0.19 & 0.983 & 55 & 1.513 \\
\hline
\end{tabular}




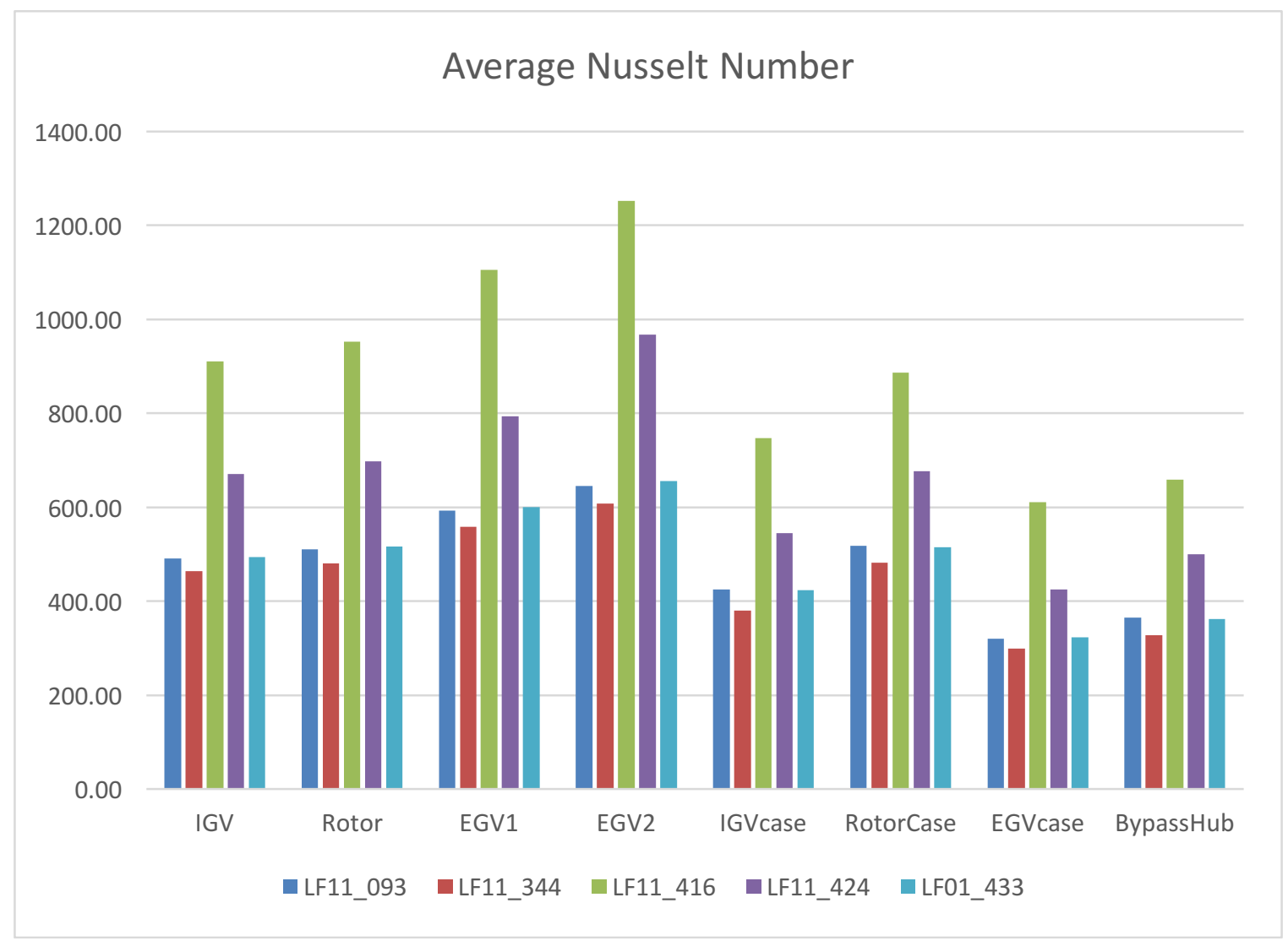

Figure 7 Average Nusselt numbers for various surfaces.

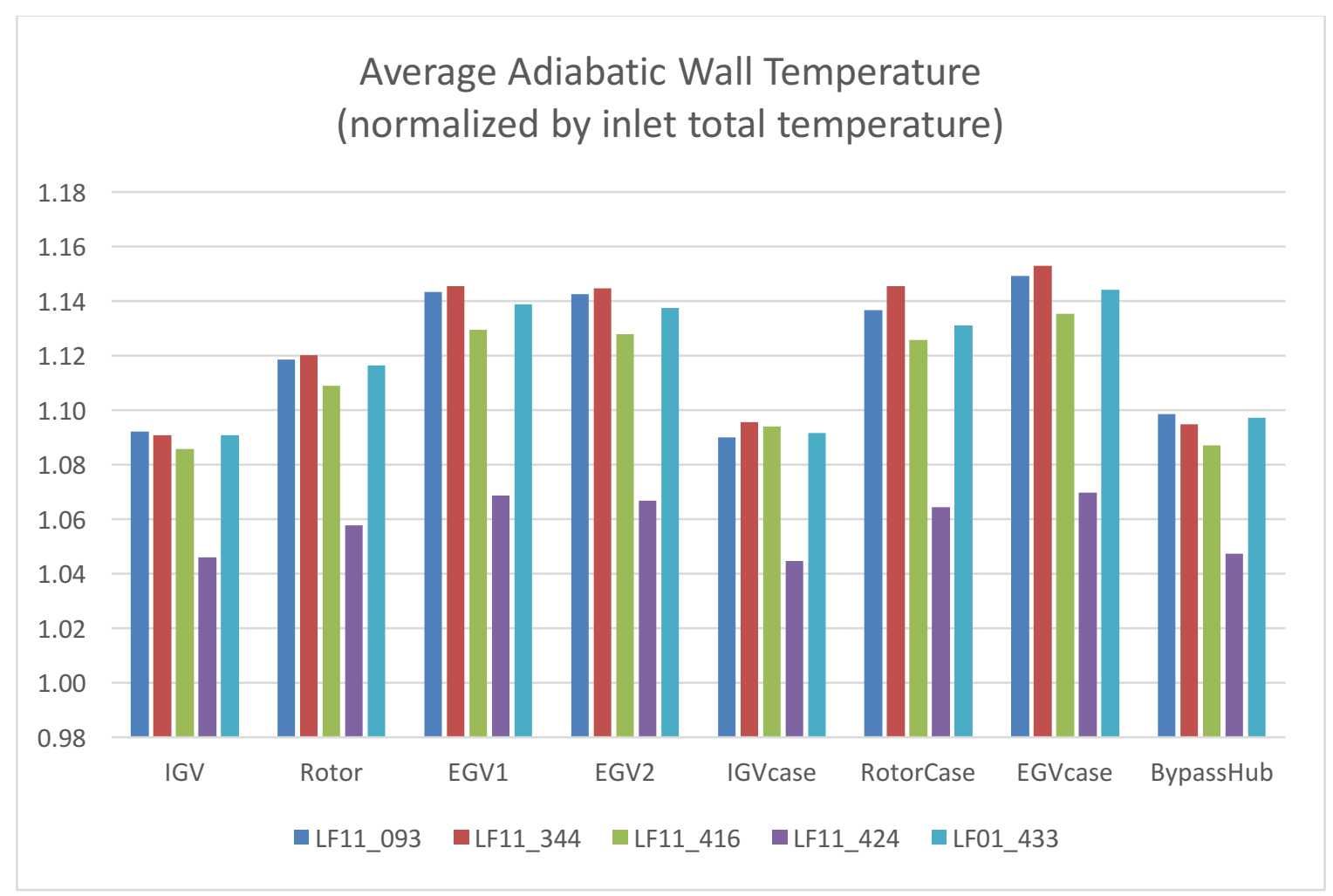

Figure 8 Average adiabatic wall temperature on various surfaces.

Page 10 of 17 


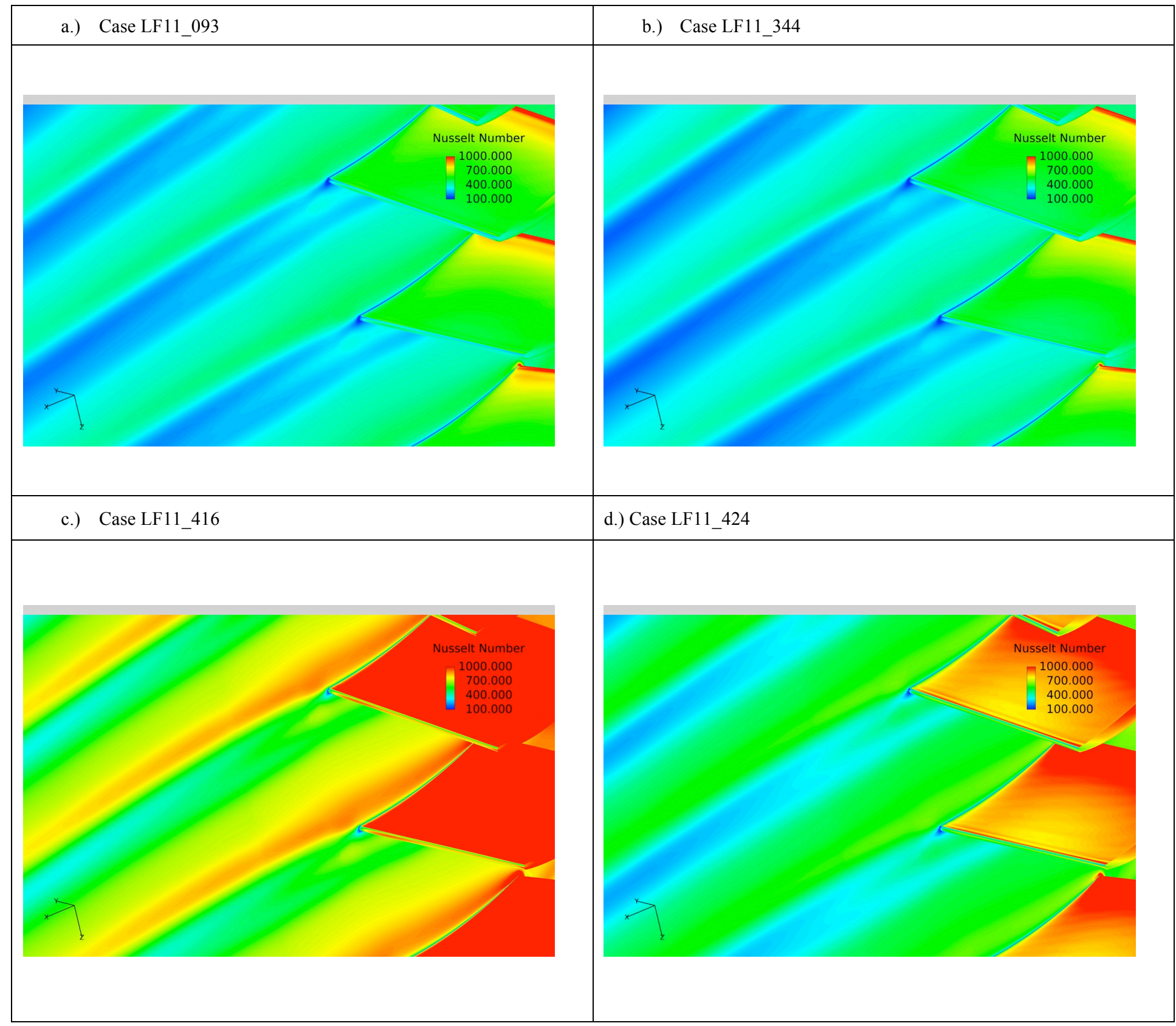

Figure 9 Nusselt number on the casing downstream of EGV2 (flow from right to left). 
a.)

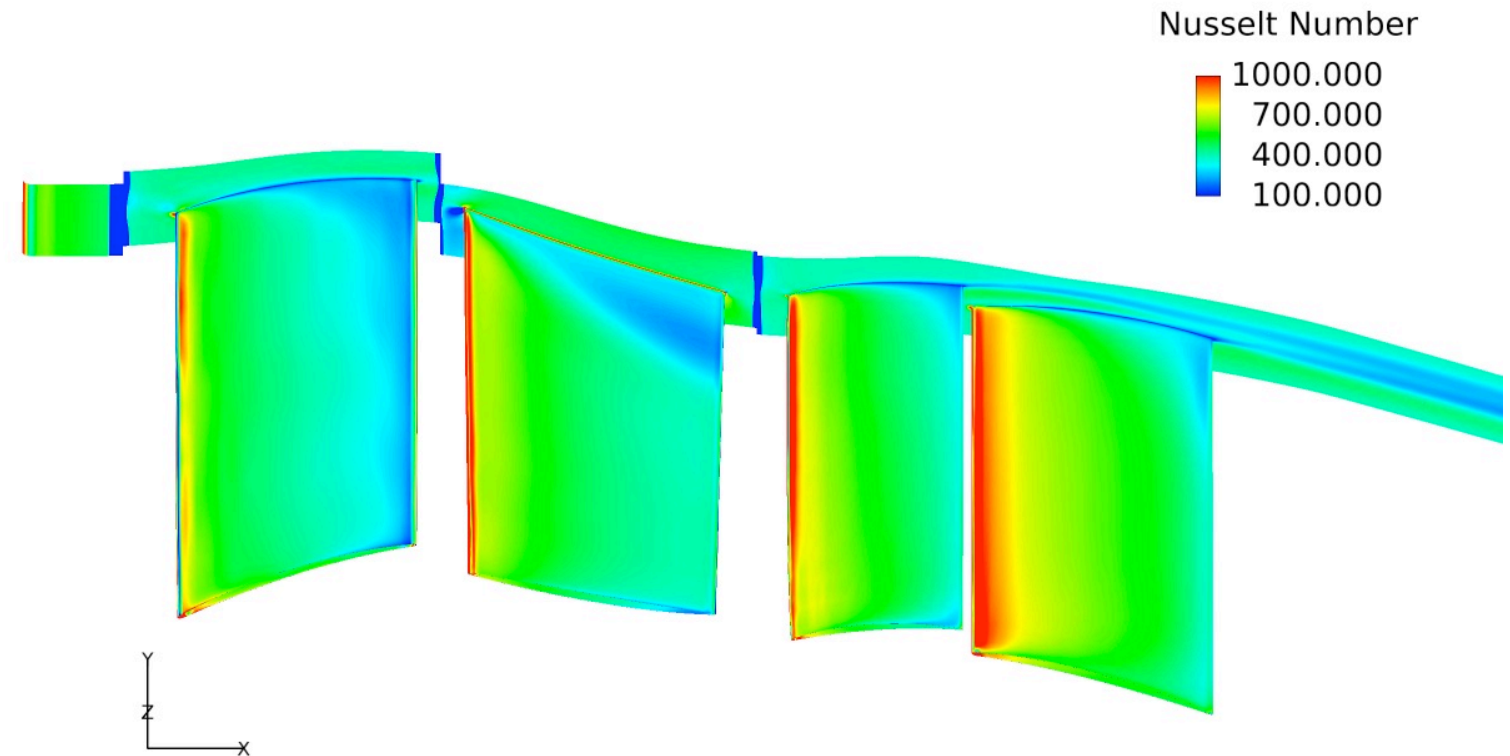

b.)

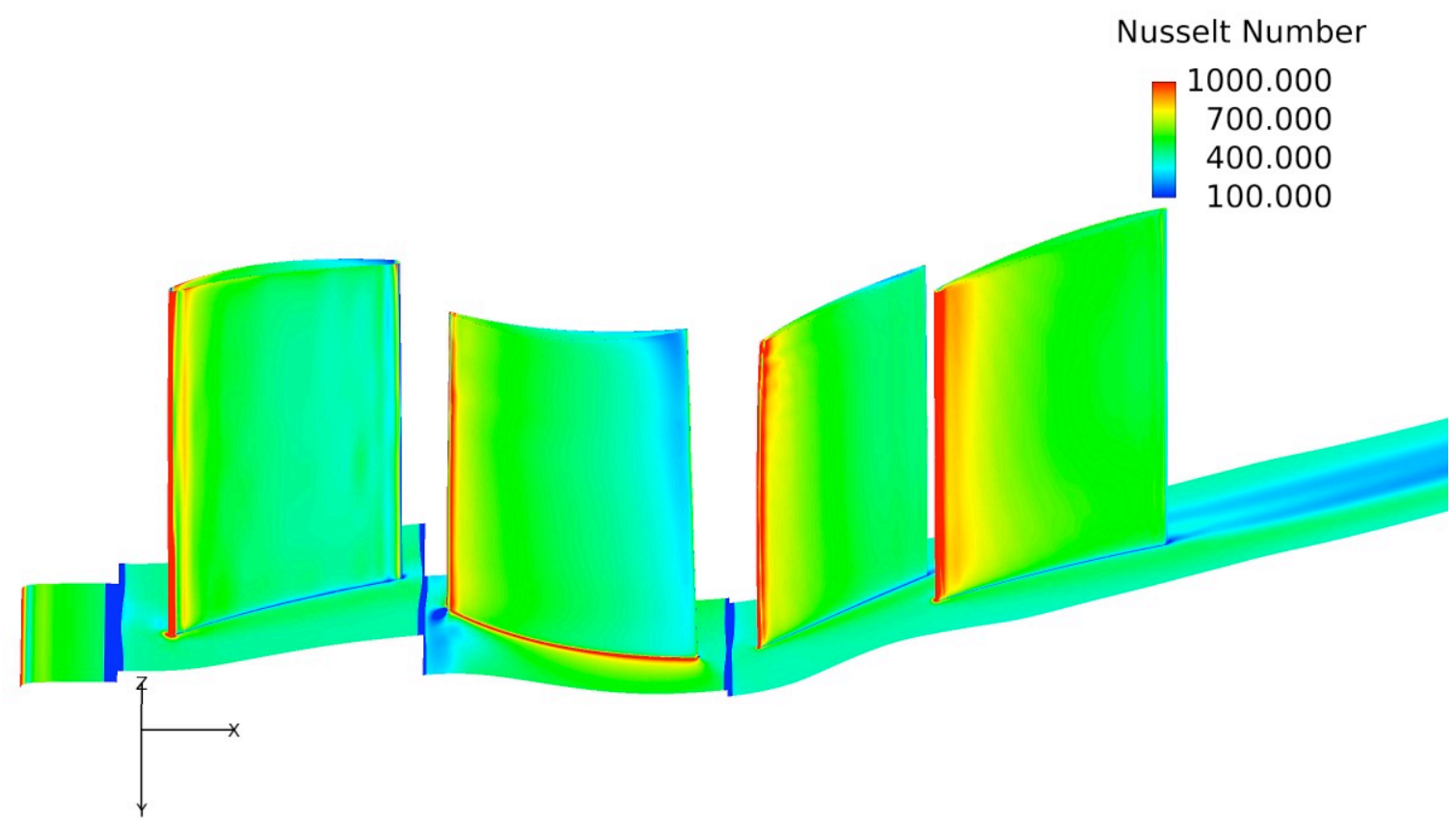

Figure 10 Case LF11 093 Nusselt number: a) Looking at stationary suction surfaces, b) Looking at stationary pressure surfaces. (flow is from left to right) 
a.)

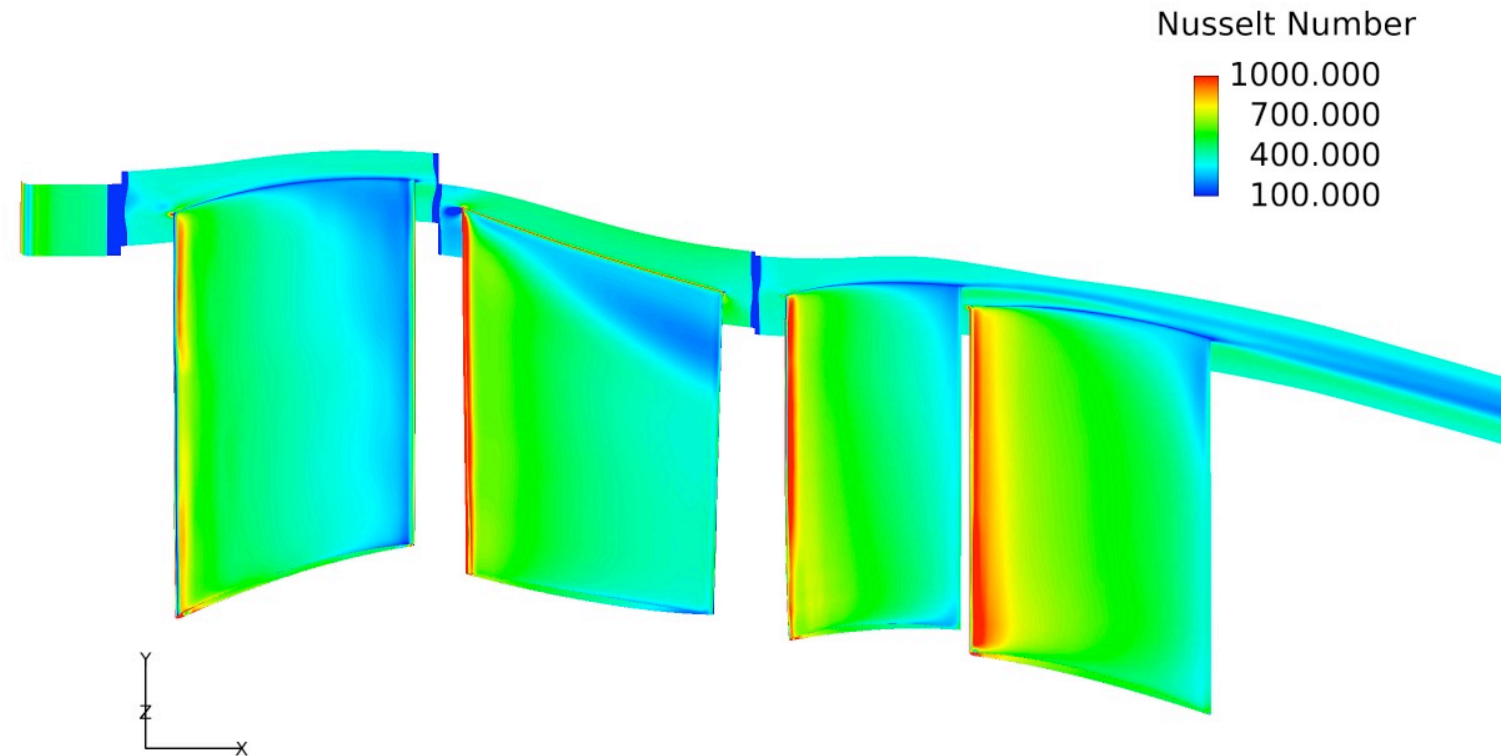

b.)

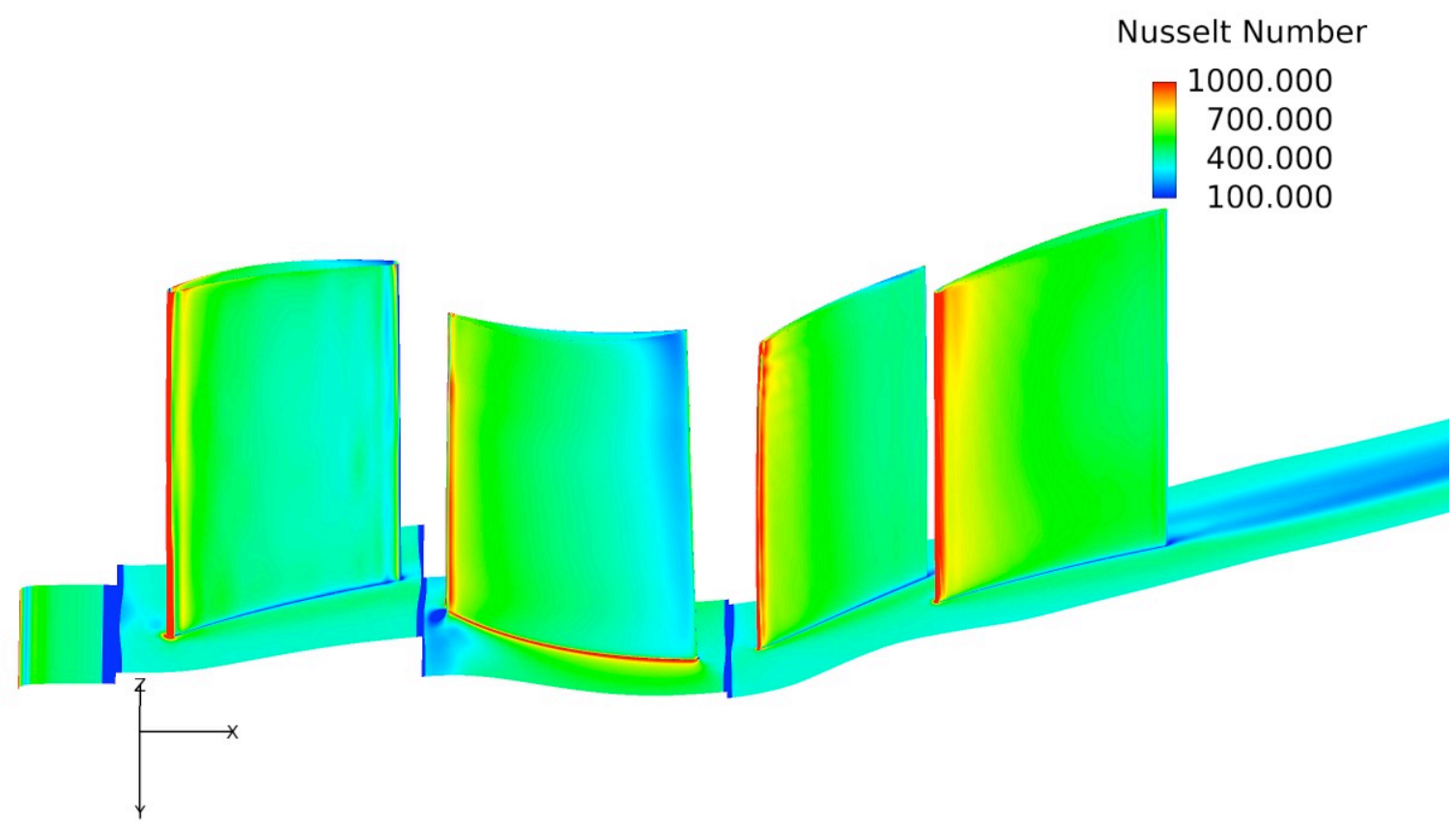

Figure 11 Case LF11 344 Nusselt number: a) Looking at stationary suction surfaces, b) Looking at stationary pressure surfaces. (flow is from left to right) 
a.)

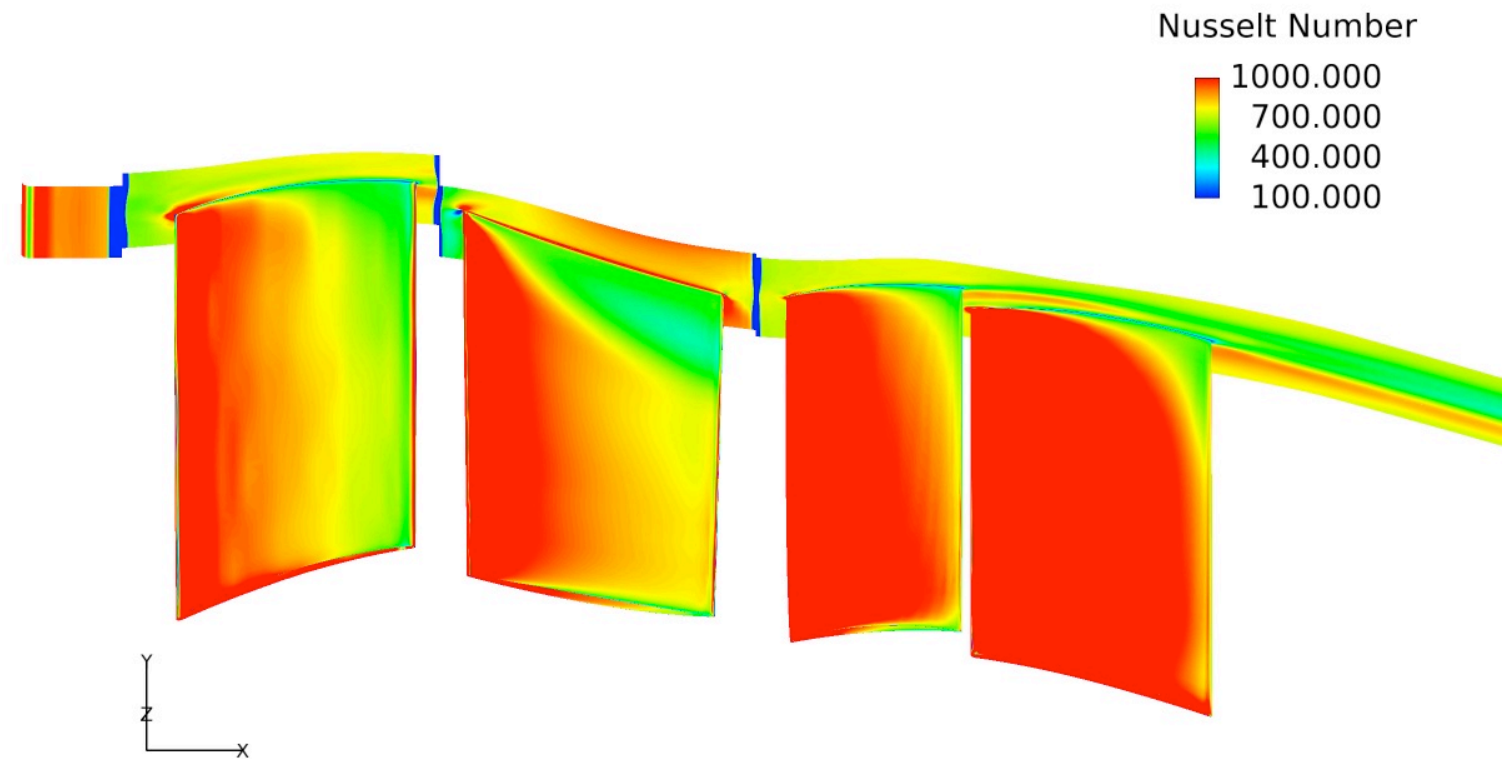

b.)

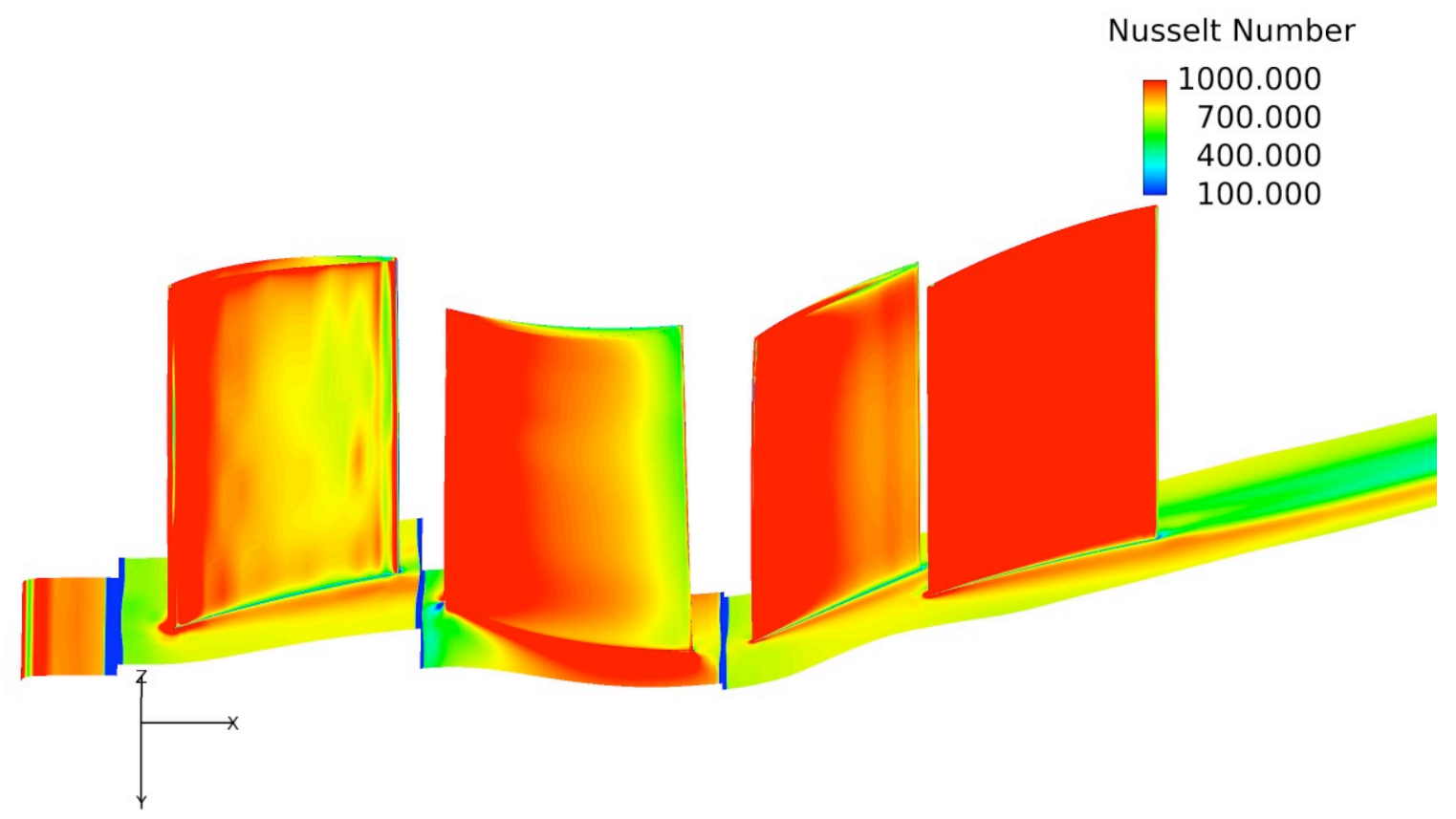

Figure 12 Case LF11_416 Nusselt number: a) Looking at stationary suction surfaces, b) Looking at stationary pressure surfaces (flow is from left to right). Note that the scale has been matched to other cases for direct comparison. In figure 15 the same result is presented using a scale that does not sacrifice detail in the high Nusselt number regions. 
a.)

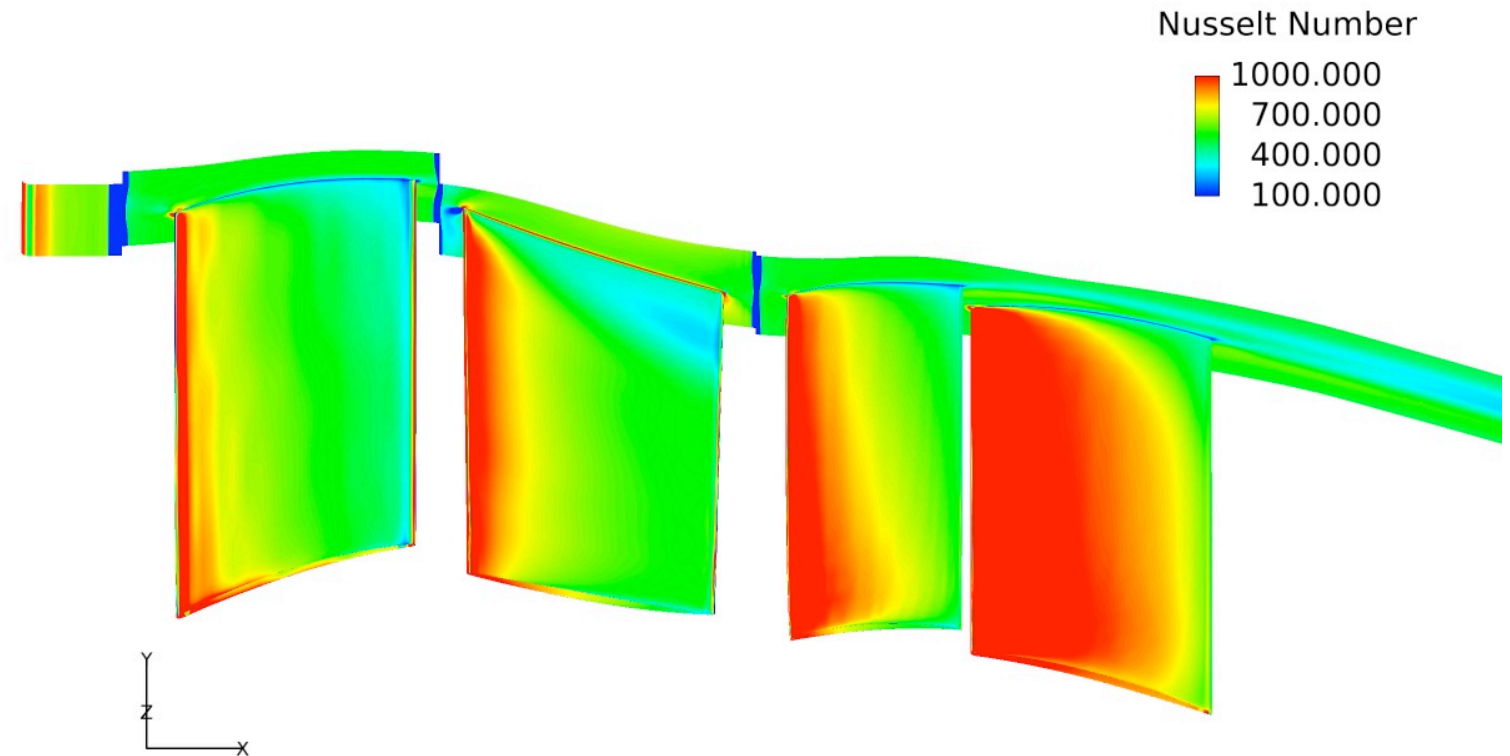

b.)

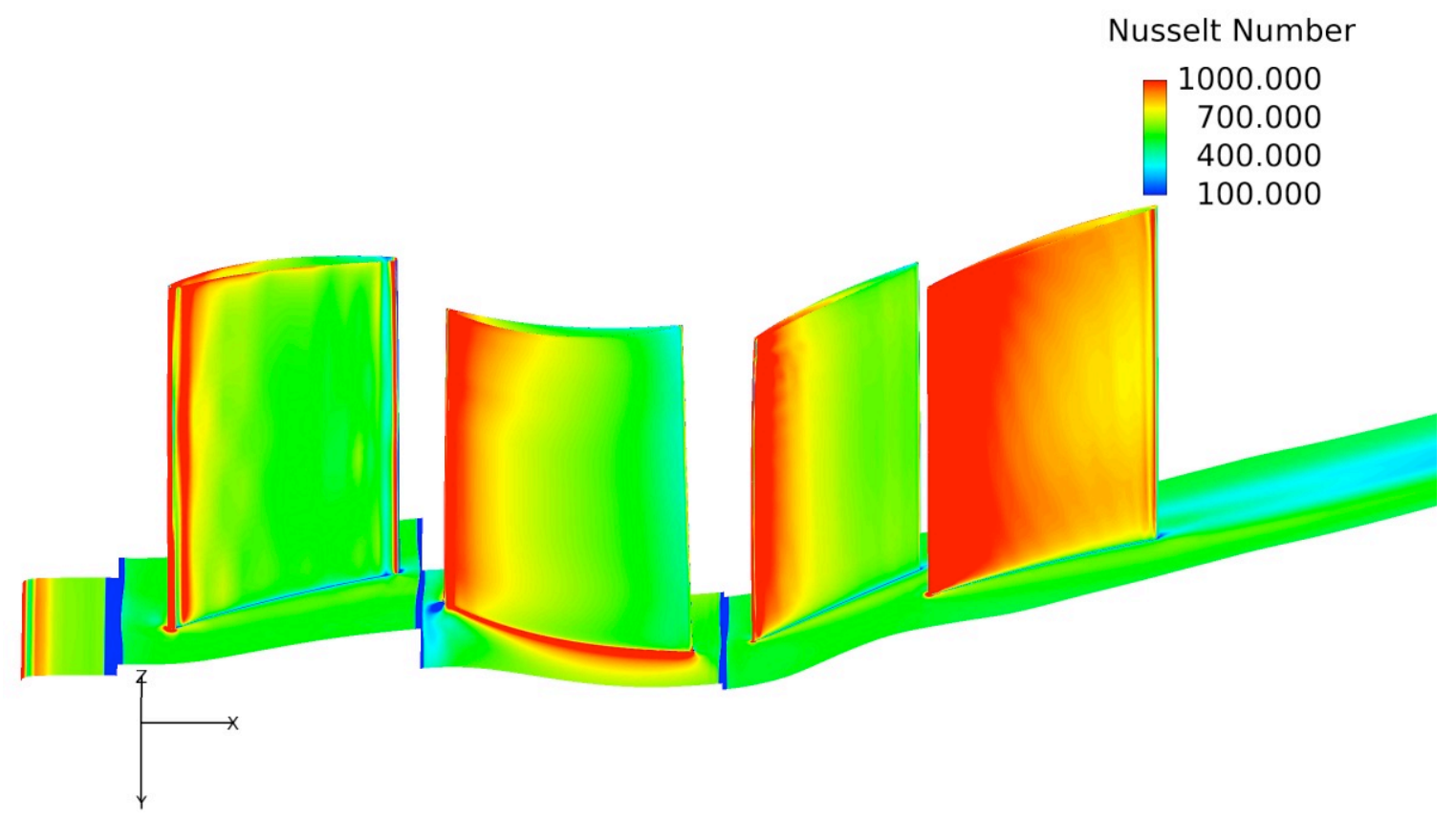

Figure 13 Case LF11 424 Nusselt number: a) Looking at stationary suction surfaces, b) Looking at stationary pressure surfaces. (flow is from left to right) 
a.)

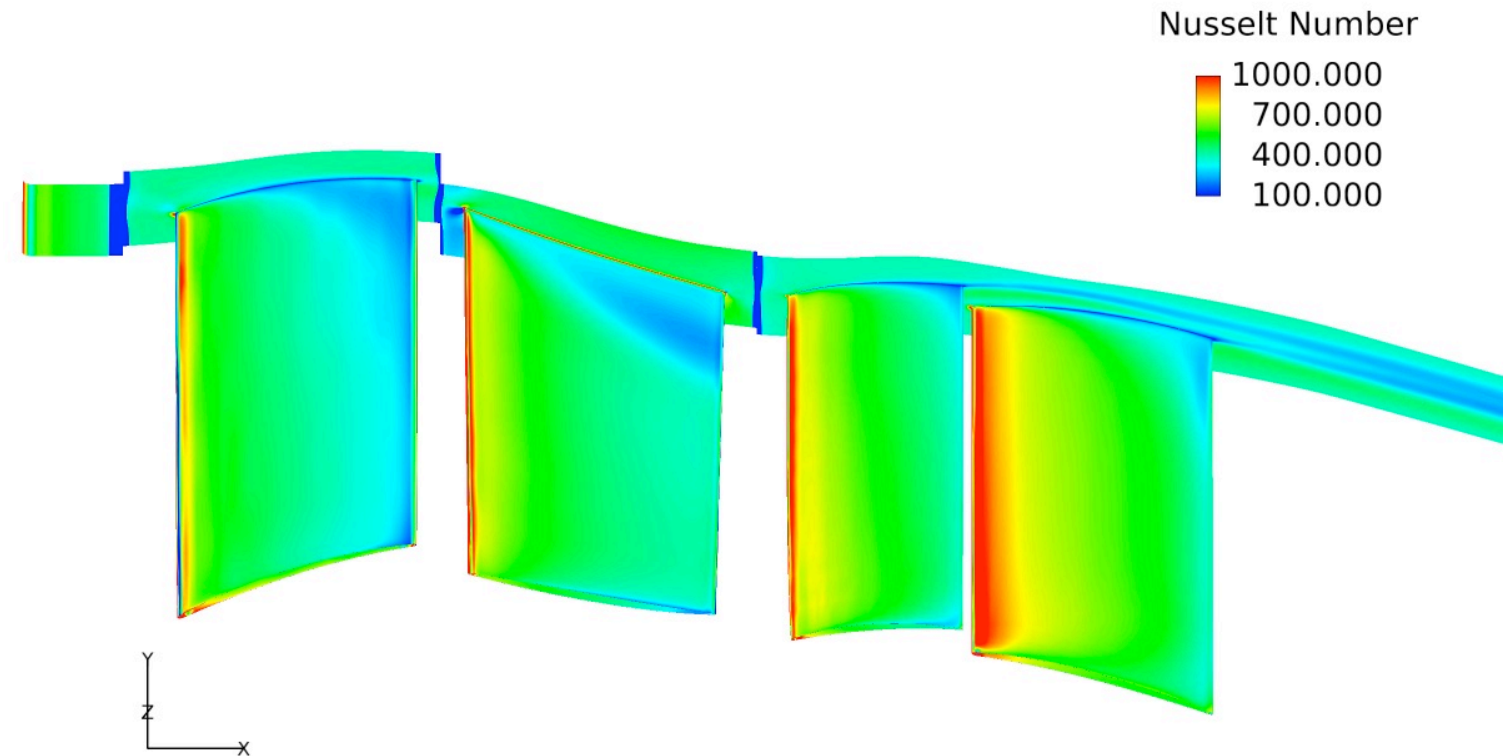

b.)

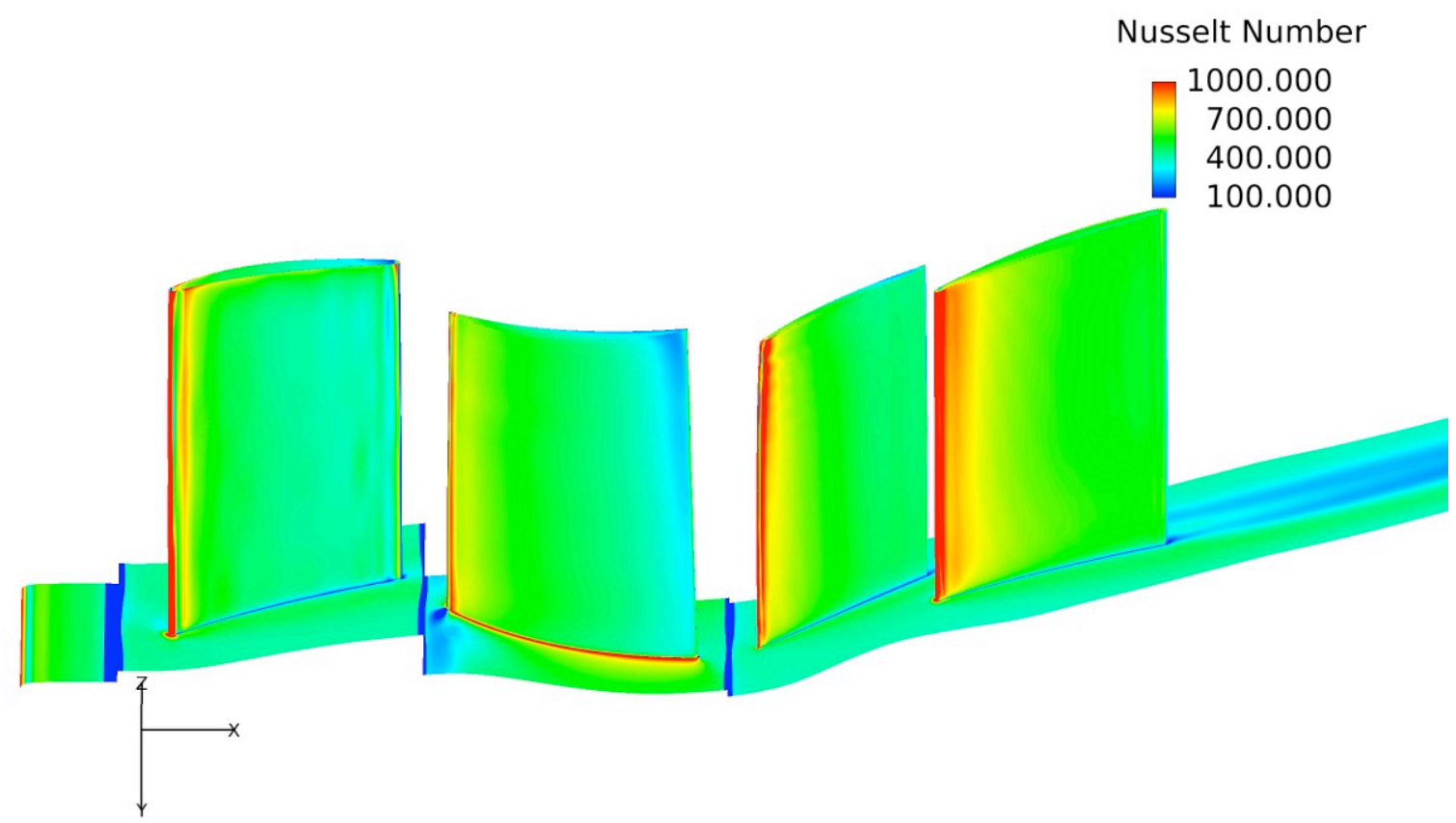

Figure 14 Case LF01 433 Nusselt number: a) Looking at stationary suction surfaces, b) Looking at stationary pressure surfaces. (flow is from left to right) 
a.)

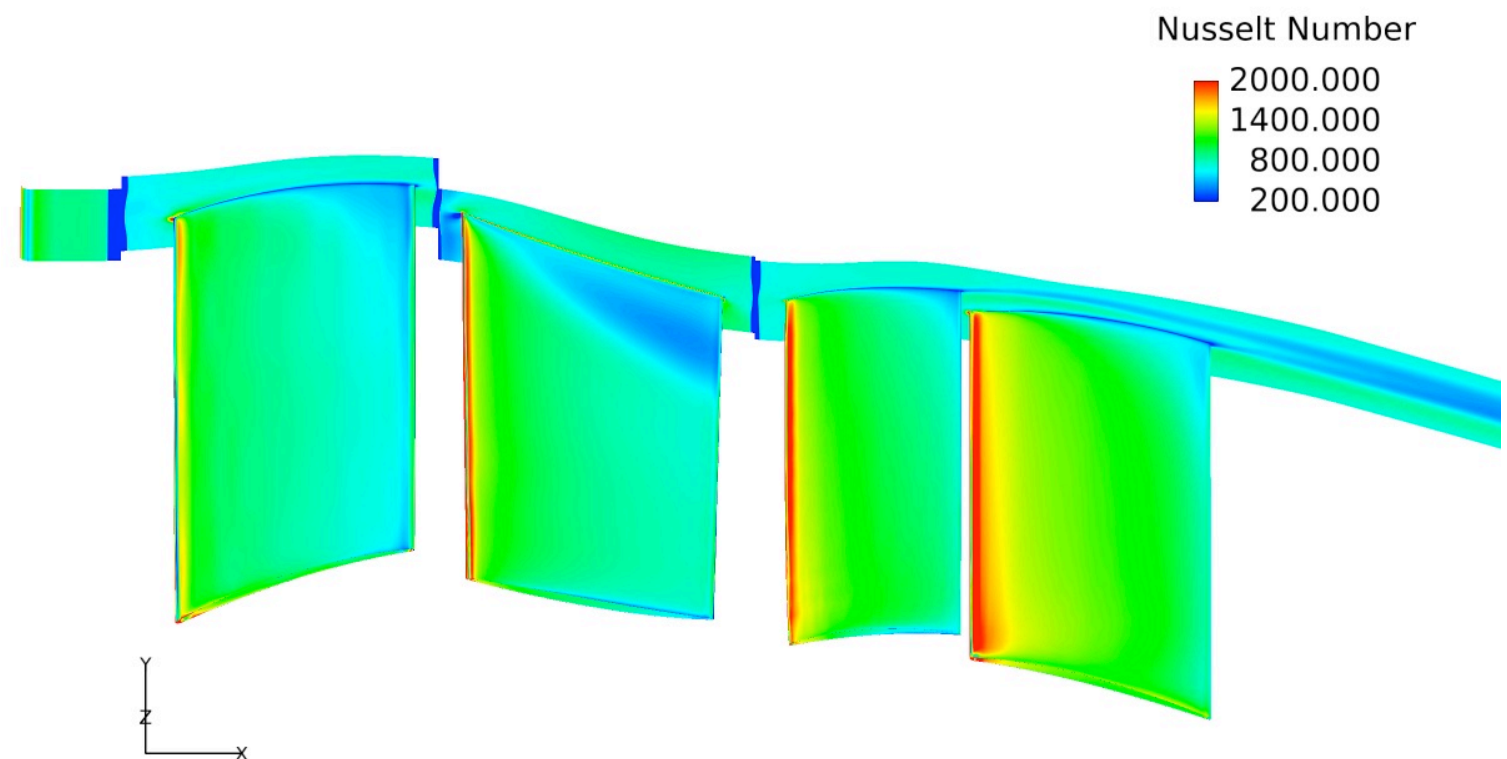

b.)

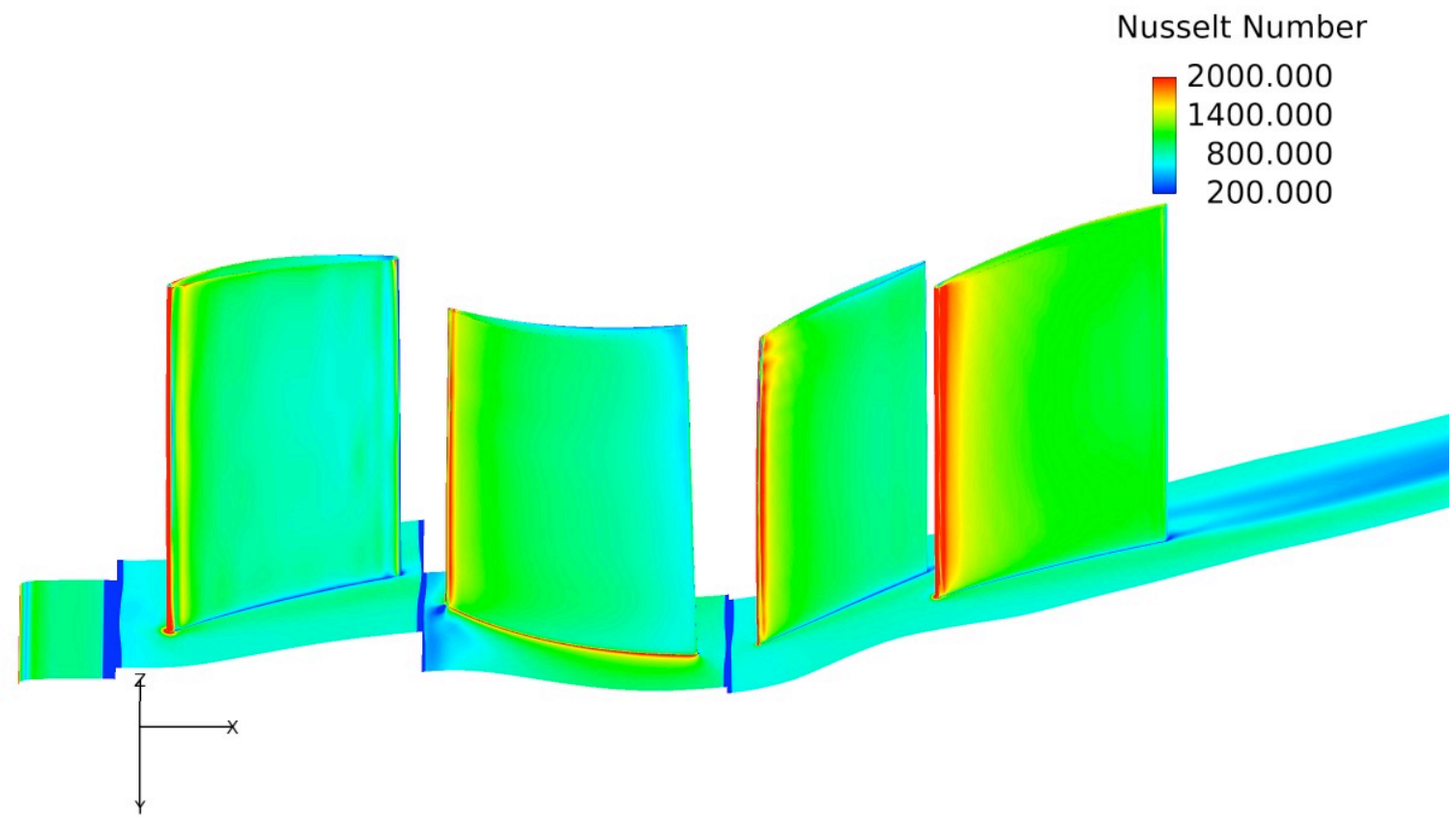

Figure 15 Case LF11_416 Nusselt number (scale increased to recover detail): a) Looking at stationary suction surfaces, b) Looking at stationary pressure surfaces. (flow is from left to right)

Page 17 of 17 